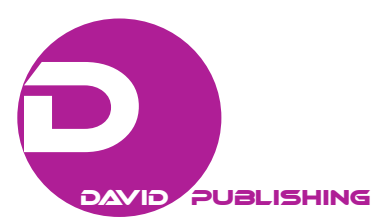

\title{
Quality-Oriented Climate and Service Quality Among Healthcare Providers: Evidence From a Rehabilitation Center in Italy
}

\author{
Anna Romiti, Daria Sarti, Chiara Lorini, Leonardo Capecchi, Martina Donzellini, Guglielmo Bonaccorsi \\ University of Florence, Florence, Italy
}

\begin{abstract}
The importance of quality in service provision is widely recognized in health service research. However, a limited number of studies have investigated antecedents of quality in healthcare service provision. This article tries to shed further light on this under-researched field. Specifically, the aim of this study is to verify the relationship between the quality-oriented climate and service quality as perceived by employees. The study was conducted in a private non-profit Rehabilitation Centre in Italy using a questionnaire administered to all healthcare workers. The questions focused on perceptions of quality-oriented climate (priorization of quality care, social cooperation, and exchange), four different connotations of the quality in healthcare provision (provision of high quality service, adequacy of time spent with patients, freedom in clinical decisions, and continuing relationships with patients), as well as on respondents' background. Of the 248 healthcare workers, 183 completed the questionnaire. Hierarchical regression analysis was used to study the relationship between quality-oriented climate and outcome variables (quality in healthcare provision). The results suggest that a quality-oriented climate does explain service quality in Healthcare settings: When an organization has implemented a quality-oriented climate, the service care provided by healthcare workers can determine an increase for three of the four investigated aspects of quality service provision (quality of care, freedom to make clinical decisions to meet patients' needs, and continuing relationships with patients). The paper demonstrates that the offer of quality services involves in a different way the various healthcare professionals and/or management staff. This research provides interesting findings for healthcare manager in Health Service settings regarding the management of a quality-oriented process of service provision.
\end{abstract}

Keywords: service climate, service quality, healthcare providers, rehabilitation center, prioritization of care, cooperation

Acknowledgements: Anna Romiti wrote: "Service quality and healthcare providers' perceptions"; Daria Sarti wrote: "Organizational determinants for healthcare quality"; Anna Romiti and Daria Sarti wrote: "Quality-oriented climate and service quality", "Measures", "Results and Discussion"; Chiara Lorini wrote: "Sample and procedures"; Anna Romiti, Daria Sarti and Guglielmo Bonaccorsi wrote: "Conclusion". All the authors wrote the "Introduction" and "Hypothesis". Martina Donzellini and Leonardo Capecchi made data entry. The authors thank Elettra Pellegrino that collaborated in data gathering.

Anna Romiti, assistant professor, Department of Experimental and Clinical Medicine, University of Florence, Florence, Italy.

Daria Sarti, Ph.D., assistant professor, Department of Economics and Management, University of Florence, Florence, Italy.

Chiara Lorini, Ph.D., researcher, Department of Health Science, University of Florence, Florence, Italy.

Leonardo Capecchi, MD, School of Specialization in Hygiene and Preventive Medicine, University of Florence, Florence, Italy.

Martina Donzellini, MD, School of Specialization in Hygiene and Preventive Medicine, University of Florence, Florence, Italy.

Guglielmo Bonaccorsi, MD, associate professor, Department of Experimental and Clinical Medicine, University of Florence, Florence, Italy.

Correspondence concerning this article should be addressed to Anna Romiti, Department of Experimental and Clinical Medicine, University of Florence, 50134, Florence, Italy. 


\section{Introduction}

In recent years, the attention of healthcare organizations towards quality and efficiency of service has been greatly increasing. Several factors have pushed in this direction. On the one hand, there is the budgetary pressure that forces organizations to use resources in the most appropriate cost-effective way. On the other hand, the pervasiveness of a patient-centered logic has given considerable attention on patients' requests in order to improve the quality of care.

The health service quality can be studied considering two points of view: those of patients and those of healthcare workers. In this study, we focus on the technical aspect of healthcare service, which is referred to the appropriateness of treatments of the service provided, evaluating employees' perspective on the basis of their perceptions.

The choice to analyze the healthcare workers' view is justified by two main reasons. On the one hand, patients are less likely to be able to assess the technical dimension of quality because of their difficulty in evaluating professional technical competence. On the other hand, the patient's focus is mostly on aspects of service provision that are quite far from the effectiveness of the healthcare process. This perspective relates to functional aspects of the service (Babakus \& Mangold, 1992) in particular on the structural aspects of the service -i.e., tangible elements - and on the way in which the service itself is provided. Despite same authors consider patient's view not significant in evaluating the service quality, most studies on healthcare quality were conducted from the perspective of the patient.

The aim of this study is to investigate one of its most important but under-studied organizational determinants of quality of the point of view of healthcare professional, the quality-oriented climate. In particular, we verify the effects of quality-oriented climate on the service quality as perceived by the employees of a non-profit rehabilitation center in Italy. According to the literature, when a healthcare worker identifies a favorable workplace climate that is oriented toward service quality, he or she is more likely to provide higher quality service to patients (Nembhard, Northrup, Shaller, \& Cleary, 2012).

The first section of the study analyzes the literature about the service quality in healthcare considering the providers' perception and the organizational determinants for healthcare quality. In the second section the hypotheses are elaborated and the methodology used in this study is explained. In the third section the results of the research are discussed. In the last section of the study the conclusion and implications for managers in Health service setting about quality-oriented process of service provision are presented.

\section{Literature Review}

\section{Service Quality and Healthcare Providers' Perceptions}

Quality in the healthcare sector has always been considered as a concept difficult to define and measure (Donabedian, 2005). Quality has been defined as "the ability to achieve desirable objectives using legitimate means" (Donabedian, 1988, p. 173). OECD (Kelly \& Hurst, 2006, p. 10) defines quality of care, on the basis of the Institute of Medicine's description, as "the degree to which health services for individuals and populations increase the likelihood of desired health outcomes and are consistent with current professional knowledge". One of the reasons for the complexity of the healthcare quality concept concerns the different perspectives on quality of different stakeholders in the sector. According to Grönroos's framework (1984), two dimensions of healthcare quality are recognized: technical and functional. Technical quality, or "intrinsic or scientific technical quality", is 
referred to accuracy of diagnoses and appropriateness of treatments; that is, solving health problems by means of knowledge and technology (Navarro-Espigares \& Hernandez Torres, 2011, p. 390). Functional quality, or "extrinsic or perceived quality", concerns the way in which a service provider delivers a service to a patient and, in particular, the patient's evaluation of the service received (Navarro-Espigares \& Hernandez Torres, 2011, p. 390). These quality types have been ascribed to two different subjects: the first to healthcare providers and the second to patients (Perleth, Jakubowski, \& Busse, 2001). Technical quality concerns the appropriateness of a service provided and the relative skills (Choi, H. Lee, Kim, \& S. Lee, 2005). In particular, according to this view, three dimensions of service - competence, outcome, and scope - are taken into account together with the care environment (Stichler \& Weiss, 2001). Since patients find it difficult to evaluate the technical quality of a healthcare service they receive (Piligrimienè \& Bučiūnienè, 2008), worker's perception has to be more taken into account, according to this perspective. Among healthcare workers, prior evidence has shown that, for example, the physician's perception of quality may depend on his/her characteristics, such as gender, years in practice, and specialty; organizational setting, such as medical school, and the size of work group; and market factors (Reschovsky, Reed, Blumenthal, \& Landon, 2001). Functional quality, on the other side, has been referred to the view of patients and, in particular, their satisfaction with the healthcare provided. A patient's difficulty to evaluate some of the most important dimensions of a healthcare service, such as physicians' technical competence, leads the same authors to consider patients' view as not significant in this sector since it is mostly based on aspects far from the effectiveness of the care process. The importance of healthcare workers' perspective, and in particular of professionals', has been thus confirmed by different studies. For example, it was found a positive correlation between professionals' perception of the determinants of hospital effectiveness and predictors of quality of patient care such as "organizational clarity, leadership competence, development, and working climate" (Hussein, 2014). Furthermore, employees' perspective about service quality has been found to be related to patients' view (Scotti \& Harmon, 2007), but in a way that is more stringent and critical than patients' view (Young, Meterko, Mohr, Shwartz, \& Lin, 2009).

Given these premises, this paper deals with measuring employees' perspective. The concept of quality adopted in this work is relative to the four quality dimensions identified by Reschovsky, Reed, Blumenthal, and Landon (2001), which are related to the four main aspects of the practice of quality in medicine: the possibility of providing high quality care to all patients, the availability of adequate time to spend with patients, the freedom to take clinical decisions that meet patients' needs, and the possibility of maintaining a relationship with patients over time.

\section{Organizational Determinants for Healthcare Quality}

A number of studies analyze the importance of quality-oriented organizational determinants on healthcare quality. Some examples of such determinants in the managerial domain of quality improvement are group-oriented culture (Kaissi, Kralewski, Curoe, Dowd, \& Silversmith, 2004), working relationships and coordination (Gittell, 2002), teamwork (Shortell, O’Brien, Carman, Foster, Hughes, Boerstler, \& O’Connor, 1995) and information technology (Restuccia, Cohen, Horwitt, \& Shwartz, 2012). Despite the widespread acceptance of the importance of quality of care in predicting performance in healthcare provision, research on its determinants remains scarce (Williams, Manwell, Konrad, \& Linzer, 2007). However, as suggested by authors, it is logical that when "organizations and their staff truly value quality, a higher quality of care is delivered" (Williams, Manwell, Konrad, \& Linzer, 2007, p. 206). As accepted by many scholars, the issue of 
initiatives for quality improvement is a complex and vague topic in a healthcare setting due to its specificities, and the general aversion toward novelties and barriers to changes that in this context are particularly severe (Karassavidou, Glaveli, \& Zafiropoulos, 2011). As noted by Shortell, Zazzali, Burns, Alexander, Gillies, Budetti, and Zuckerman (2001), physicians' organizations often lack a sense of psychological identity as a "group" in so much as these organizations can be seen more as "a collection of physicians cobbled together under the legal umbrella of constituting a group" (Shortell, Zazzali, Burns, Alexander, Gillies, Budetti, \& Zuckerman, 2001, p. 74). This makes it difficult to develop identification with the organization as opposed to the identification with the individual profession and their "community of professionals". Therefore, the presence of professionals, dominant and established working patterns, and entrenched power dynamics (Degeling, Kennedy, \& Hill, 2001) leads to the creation of "professional groups" within an organization that tends to embody different values, attitudes, and orientation and, in turn, sub-cultural behavioral patterns. To express such a state, some authors define the contexts of healthcare as "an amalgam" of heterogeneous and interacting sub-cultures, such as those existing within distinct professional groups, divisions, and teams. In this vein, it is claimed that the presence of professional sub-cultures may represent a barrier to managed-led quality initiatives (Karassavidou, Glaveli, \& Zafiropoulos, 2011). Therefore, while the co-existence of different sub-cultures has positive consequences - such as enabling professionals to develop new knowledge and extend cultural boundaries (Morgan \& Ogbonna, 2008) - it also leads to negative consequences stemming from the need to manage sub-cultural differences and their interactions, overcome cultural barriers, and manage related conflicts within an organization. In fact, professionals' view of their work may conflict administrative forms of work, thus fostering a bureaucrat-professional dispute (Wallace, 1995). This may be more emphasized when dealing with processes of rationalization and quality improvement. Taking into account of these peculiarities, a change in attitudes towards quality improvement in the healthcare context can occur by altering daily policies, practices, and routines; and placing emphasis on challenging basic organizational assumptions. Situational factors, such as climate and culture, are known to have an important role in channeling technical capability into productive behavior. Scholars also suggest the importance of climate and culture in affecting health service-related outcomes (Gershon, Stone, Bakken, \& Larson, 2004). Many contributions in current literature highlight the difference between climate and culture (see, for example: Gershon, Stone, Bakken, \& Larson, 2004; Denison, 1996). Organizational climate can be considered as a determinant of healthcare quality as perceived by caregivers. In fact, it is recognized that this construct represents a derivate of organizational culture, and is a less broad concept compared to organizational culture. Further, it presents a more direct connection to open behavior, events, rules, and routines (Karassavidou, Glaveli, \& Zafiropoulos, 2011). The concept of organizational climate was introduced more than half a century ago by Lewin, Lippit, and White (1939), who defined it as shared perceptions and beliefs that shape how organizations work. Later, other authors studied organizational climate with regard to the goals organizations may pursue; for example, a climate that results when the organization pursues a goal of either safety or innovation (Schneider, Brief, \& Guzzo, 1996). Some recent studies have highlighted quality-oriented climate and its positive impact on service quality in the healthcare sector (Nembhard, Northrup, Shaller, \& Cleary, 2012; Young, Meterko, Mohr, Shwartz, \& Lin, 2009).

\section{Quality-Oriented Climate and Service Quality}

Quality-oriented climate is defined as one in which organizational policies and behavior, as perceived by 
caregivers, emphasizes patient satisfaction and technical quality of care, and which "encourages all employees to pay close attention to customer opinions and attitudes" (Young, Meterko, Mohr, Shwartz, \& Lin, p. 1129). According to scholars interested in understanding employees' attitude towards quality in healthcare settings, different dimensions might be of interest as particularly conductive of quality-oriented climate (Nembhard, Northrup, Shaller, \& Cleary, 2012), these are: the prioritization of quality care, high-quality relationships between staff, and open communication. Organizational prioritization of quality care is "the extent to which emphasis on quality care permeates the organization's mission and action" (Nembhard, Northrup, Shaller, \& Cleary, 2012, p. 76). It represents the general system of practices and conduct implemented by the senior management in order to promote quality across the organization. Specifically, importance is given to the communication flows from the top of the organization to its bottom in order to share information on quality improvements, initiatives, and practices. Researchers recognize the importance of senior management prioritization on quality in healthcare settings and a number of notable healthcare institutions committed to improving service quality programs are performing exceptionally well (Glickman, Baggett, Krubert, Peterson, \& Schulman, 2007). However, there is still a lack of empirical studies to prove a link between an organizational view of prioritization of quality by the senior management and healthcare service quality.

Also the seminal work by Nembhard, Northrup, Shaller, and Cleary (2012) considers high quality relationships between staff as the interpersonal dynamics for quality that is an interactional aspect related to relationships that exist between service providers involved in a common work process (Nembhard, Northrup, Shaller, \& Cleary, 2012). This concept has been previously theorized in different ways, such as relational coordination (Gittell, 2002), and internal service quality (Hallowell, Schlesinger, \& Zornitsky, 1996). The importance of individuals' interactions in service operations is noted because of the specificities that identify the service work processes - which have high levels of uncertainty, high time constraints, and the need for iterative interactions among care providers due to a reciprocal interdependence that often characterizes the provision of a service (Gittell, 2002). These close relationships between individuals enable them to detect errors, reducing mistakes by pooling problem-solving skills and it also allows generalized learning behaviors (Brueller \& Carmeli, 2011). Also, they are characterized by trust and cooperation among care providers, and are positively related to service provision quality. The last and third dimension of quality-oriented climate is open communication that is, "when individuals express their thoughts without fear of punishment or any other negative repercussion" (Nembhard, Northrup, Shaller, \& Cleary, 2012, p. 76). In order to promote a quality-oriented climate in healthcare institution, optimization of communication and social networking is needed in order to "break down hierarchies and divisions that limit information sharing" (Glickman, Baggett, Krubert, Peterson, \& Schulman, 2007, p. 343). Therefore, when a caregiver identifies a favorable workplace climate oriented towards service quality - he/she also perceives a higher degree of quality in the service provided in terms of the overall quality of care delivered to patients. Also, quality-oriented climate is also expected to directly influence specific aspects of service provision that may represent key facets in the perceived technical dimension of quality. It allows professionals to exercise the kind of autonomy that belongs to their profession. The professional autonomy mentioned is related to different aspects of medical care and practices, such as the right to make clinical decisions or the opportunity to decide on the amount of time to spend with patients and the continuity of the relationship. Therefore, when the professional perceives a favorable working climate committed to service quality, the perception of the quality of service will be better not only in terms of the overall quality of care but also in each single key aspect of the service provided. 


\section{Hypothesis}

On the basis of the above-mentioned aspects, this paper will focus on climate as a determinant and a facilitator of quality-oriented behavior both in terms of overall quality of care as perceived by employees and on single key aspects of service provided.

This leads to proposing the following four hypotheses:

$\mathrm{Hp1}$ : The higher the level of workplace climate oriented toward service quality, the greater the level of the quality of care provided to all patients.

Hp2: The higher the level of workplace climate oriented toward service quality, the greater the level of adequacy of time spent with patients.

Hp3: The higher the level of workplace climate oriented toward service quality, the greater the level of freedom in making clinical decisions.

Hp4: The higher the level of workplace climate oriented toward service quality, the greater the level of continuing relationships with patients.

\section{Research Design}

\section{Methods}

To demonstrate the hypothesis of this study, an investigation was carried out in a private non profit Rehabilitation Centre in Italy. Data were collected from questionnaire administered to 183 employees.

\section{Sample and Procedure}

The examined rehabilitation center is a private structure, publicly accredited by the Tuscany region, which operates in a shared professional relationship with public health units. There are two factors that determine the "public" modus operandi of this organization. On the one hand, as mentioned, the accreditation obtained from the regional public health service lets the center operate in favor of citizens in accordance with the same standard set of rules and access modes as public structures. On the other hand, the absence of a private healthcare market in Tuscany leads the center to provide rehabilitation services as if it were a public structure, according to the regional tariffs set by local authorities, thus shaping itself as a "private" organization funded and "controlled" by public health authorities. Not by chance, the rehabilitation pathways adopted here are almost always referred to and shared with subjects discharged from public health facilities.

The center offers multi-specialist rehabilitation (neurology, orthopedics, cardiology, pulmonology, and spine pathology). The healthcare force is represented by physicians, physiotherapists, healthcare assistants, nurses, and healthcare workers in different services (speech therapy, radiology, and psychological assistance). In order to carry out the analysis, the project was shared with the top management of the healthcare center. The data were collected over the July-December 2014 period, using a questionnaire administered anonymously during a training course cycle, with the support of the management, to all healthcare workers of the center. The questions focused on, among other things, respondents' perceptions of quality of care and quality-oriented climate as well as on respondents' background aimed at acquiring other individual information (such as age, gender, nationality, education, role in the structure, seniority in the job and the structure, operative unit of affiliation, and working relationship and working hours). Of the 248 healthcare workers at the center, 183 completed the questionnaire resulting in a $73.8 \%$ response rate. Table 1 reports the descriptive analysis of the sample. The majority of respondents were Italian $(89.1 \%)$, and the mean age was 40.4 years $(S D=9.8)$. The education level was, 
generally, high: $58.6 \%$ were graduates and $19.1 \%$ were post-graduates. The highest percentage of respondents were from physiotherapists (33.9\%) and nurses (26.2\%), the majority of whom began working in the center during the past 10 years $(55.9 \%)$ and worked full-time $(62.5 \%)$.

Table 1

Descriptive Analysis of the Sample $(N=183)$

\begin{tabular}{|c|c|c|c|}
\hline & & $\mathrm{N}$ & $\%$ \\
\hline \multirow{2}{*}{ Gender } & Male & 51 & 28.2 \\
\hline & Female & 130 & 71.8 \\
\hline \multirow{4}{*}{ Age } & $20-30$ & 34 & 19.1 \\
\hline & $31-40$ & 66 & 37.1 \\
\hline & $41-50$ & 46 & 25.8 \\
\hline & $>50$ & 32 & 18.0 \\
\hline \multirow{5}{*}{ Role } & Physician & 28 & 15.3 \\
\hline & Physiotherapist & 62 & 33.9 \\
\hline & Nurse & 48 & 26.2 \\
\hline & Healthcare assistant & 29 & 15.8 \\
\hline & Others & 16 & 8.7 \\
\hline \multirow{6}{*}{ Operative units } & Orthopedics & 62 & 33.9 \\
\hline & Spinal pathologies & 43 & 23.5 \\
\hline & Neurology & 72 & 39.3 \\
\hline & Pulmonology & 43 & 23.5 \\
\hline & Cardiology & 40 & 21.9 \\
\hline & Others & 67 & 36.6 \\
\hline \multirow{4}{*}{ Working relationship } & Permanent contract & 133 & 72.7 \\
\hline & Fixed-term contract & 28 & 15.3 \\
\hline & Free lance & 18 & 9.8 \\
\hline & Others & 4 & 2.2 \\
\hline \multirow{3}{*}{ Working hours } & Part time ( $<30$ hours/week) & 56 & 31.8 \\
\hline & Full time (30-40 hours/week) & 115 & 65.3 \\
\hline & $>40$ hours/week & 5 & 2.8 \\
\hline
\end{tabular}

\section{Measures}

In this work, scales used were already validated in previous studies on healthcare (Nembhard, Northrup, Shaller, \& Cleary, 2012; Reschovsky, Reed, Blumenthal, \& Landon, 2001). Responses were measured on a five-point Likert scale with 1 referring to "strongly disagree" and 5 referring to "strongly agree".

Measures: dependent variables. Quality of care was measured by using four different variables, each expressed as a single-item question and identified in a previous study by Reschovsky, Reed, Blumenthal, and Landon (2001). Specifically, the authors suggest that four aspects of quality are relevant in healthcare as perceived by healthcare providers: high quality in provision, that is a professional's perception of providing high quality care to all patients; adequacy of time with patients, that is a healthcare worker's perception that he or she has adequate time to spend with patients during office visits; freedom in clinical decisions, that is the perception that healthcare workers have about the amount of freedom they enjoy in making clinical decisions that meet their patients' needs; and continuing relationship with patients, representing the perception that professionals have the opportunity to maintain continuing relationships with patients over time that help in promoting the delivery of high quality care. 
Table 2

Matrix of Components Rotated-Independent Variables

\begin{tabular}{lll}
\hline & Component 1 & Component 2 \\
\hline Senior management shows by its actions that quality is a top priority in this organization & 0.795 & 0.349 \\
I have a clear understanding of the organization's mission, vision, and values & 0.839 & 0.112 \\
I know of one or more quality initiatives going on within our organization this year & 0.817 & 0.283 \\
Results of our quality improvement efforts are measured and communicated regularly to staff & 0.785 & 0.386 \\
There is good information flow among departments to provide high-quality patient safety and care 0.730 & 0.470 \\
I am satisfied with the information that I receive from management and what's going on in the & 0.755 & 0.453 \\
organization & 0.221 & 0.763 \\
I observe a high level of cooperation among all members of my work unit or department & 0.346 & 0.747 \\
There is a climate of trust in my department or work unit & 0.196 & 0.822 \\
I feel free to express my opinion without worrying about the outcome & 0.331 & 0.770 \\
Staff will freely speak up if they see something that may improve patient care or affect patient safety & 0.425 & 0.777 \\
The climate in the organization promotes the free exchange of ideas &
\end{tabular}

Measures: independent variable. As independent variable, it was used the quality-oriented climate, as identified in a previous work by Nembhard, Northrup, Shaller, and Cleary (2012). The original scale developed by the authors was composed by three scales that are prioritization of quality care measured with seven items (example of item used: "Senior management shows by its actions that quality is a top priority in this organization"); high quality relationships between staff assessed using a two-item scale (example of item used: "I observe a high level of cooperation among all members of my work unit or department") and open communication measured with three items (example of item for this scale is: "The climate in the organization promotes the free exchange of ideas"). In order to assess the appropriateness of the measure for employees in this context, i.e., Italian rehabilitation center, an explorative factor analysis (EFA) was conducted on the 12 items of the original scale of organizational climate for quality (Nembhard, Northrup, Shaller, \& Cleary, 2012) with orthogonal rotation (varimax). The Kaiser-Meyer-Olkin measure verified the sampling adequacy for the analysis, KMO = 0.904 ("superb" according to Field (2009), and all, except one, KMO values for individual items were > 0.62 which is above the acceptable limit of 0.5 (Field, 2009). A single item "People here feel a sense of urgency about improving quality of patient care and service" showed a KMO value of 0.46 that is below the acceptable limit. Therefore, according to the results and also considering the specific setting of this study, it was decided not to include that item into the analysis. Therefore, the KMO measure for sample adequacy was run for the remaining 11 items resulting in $\mathrm{KMO}=0.904$. Bartlett's test of sphericity $\chi^{2}(66)=1426.40, p<0.001$, indicated that correlations between items were sufficiently large for EFA. An initial analysis was run to obtain eigenvalues for each component in the data. Two components had eigenvalues over Kaiser's criterion of 1 and in combination explained $68.41 \%$ of the variance. The items that cluster on the same components in this study suggest that component 1 represents prioritization of quality by the organization composed of six out of the seven items of the original scale (Nembhard, Northrup, Shaller, \& Cleary, 2012) and component 2 matches together the five items of the two original scales of: high quality relationship between staff and open communication. This second component was here named as social cooperation and exchange. The result differs in terms of the number of components, indeed in the previous original study, quality-oriented climate was measured through three different sub-scales. However, the reason may arise from the specific kind of health setting that in the previous study was primary care clinics (Nembhard, Northrup, Shaller, \& Cleary, 2012), while in the current work, employees in 
rehabilitation centers are investigated. Table 2 shows the factor loadings after rotation. The mean value was calculated for the two scales measuring the independent variable, and their reliability was tested using Cronbach's alpha. All alpha values were higher than the 0.70 criterion (Nunnally, 1978).

Measures: control variables. The control variables included in the regression models were gender, age, the operative unit of affiliation - such as orthopedics, spinal pathology, neurology, pulmonology, cardiology, among others - the number of working hours, the role in the structure — such as a physician, a physiotherapist, a nurse, a healthcare assistant, among others - and work relationship - such as a permanent contract, a fixed-term contract, freelance, among others. These variables were included as they have been found to be associated with quality healthcare professional perception (Reschovsky, Reed, Blumenthal, \& Landon, 2001).

\section{Results and Discussion}

First, descriptive statistics of the variables examined in the current study were explored using the statistical package, SPSS (Version 22.0). The mean, standard deviation and correlations are reported in Table 3.

Table 3

Mean, Standard Deviation and Correlations $(N=183)$

\begin{tabular}{llllllll}
\hline & Mean & SD & 1 & 2 & 3 & 4 & 5 \\
\hline 1. Adequacy of time with patients & 3.14 & 1.10 & 1 & & & & \\
2. Freedom in clinical decisions & 3.66 & 0.94 & $0.410^{* *}$ & 1 & & & \\
3. Continuing relationships with patients & 3.17 & 1.09 & $0.411^{* *}$ & $0.439^{* *}$ & 1 & & \\
4. High-quality provision & 3.23 & 1.03 & $0.549^{* *}$ & $0.535^{* *}$ & $0.508^{* *}$ & 1 & \\
5. Prioritization of quality care & 3.19 & 0.90 & $0.247^{* *}$ & $0.371^{* *}$ & $0.354^{* *}$ & $0.532^{* *}$ & \\
6. Social cooperation and exchange & 3.31 & 0.92 & $0.297^{* *}$ & $0.463^{* *}$ & $0.431^{* *}$ & $0.524^{* *}$ & \\
\hline
\end{tabular}

Note. $* p<0.01 ; * p<0.001$.

All variables were significantly correlated. The results of the correlation analysis show a positive and significant correlation existing between both the two factors of quality-oriented climate and the four dimensions of service quality. However, when all the independent variables measuring quality-oriented climate are considered together in the regression analysis, the cumulative results show some peculiarities among the four different aspects of service quality. Indeed, in order to verify the hypotheses, four multiple regression analyses were conducted for each of the four dependent variables measuring service quality. The results are presented in Table 4.

Table 4

Regression Analyses $(N=183)$

\begin{tabular}{llllll}
\hline VARIABLES & & $\begin{array}{l}\text { High quality in } \\
\text { provision }\end{array}$ & $\begin{array}{l}\text { Adequacy of time } \\
\text { with patients }\end{array}$ & $\begin{array}{l}\text { Freedom in } \\
\text { clinical decisions }\end{array}$ & $\begin{array}{l}\text { Continuing } \\
\text { relationships } \\
\text { with patients }\end{array}$ \\
\hline $\begin{array}{l}\text { Gender }^{\mathrm{a}} \\
\text { Age (years) }\end{array}$ & & -0.038 & 0.010 & -0.048 & 0.032 \\
& & 0.042 & -0.012 & -0.099 & 0.013 \\
\hline \multirow{3}{*}{$\begin{array}{l}\text { Operative units } \\
\text { of affiliation }\end{array}$} & Orthopaedics $^{\mathrm{b}}$ & 0.103 & 0.008 & 0.074 & 0.092 \\
& Spinal pathologies $^{\mathrm{b}}$ & -0.054 & -0.051 & -0.094 & -0.128 \\
& Neurology $^{\mathrm{b}}$ & -0.024 & -0.031 & 0.143 & -0.151 \\
& Culmonology $^{\mathrm{b}}$ & -0.152 & -0.074 & -0.100 & -0.105 \\
& Cardiology $^{\mathrm{b}}$ & 0.088 & 0.020 & 0.115 & -0.032 \\
\hline
\end{tabular}


Table 4 continued

\begin{tabular}{|c|c|c|c|c|c|}
\hline \multicolumn{2}{|c|}{ VARIABLES } & $\begin{array}{l}\text { High quality in } \\
\text { provision }\end{array}$ & $\begin{array}{l}\text { Adequacy of time } \\
\text { with patients }\end{array}$ & $\begin{array}{l}\text { Freedom in } \\
\text { clinical decisions }\end{array}$ & $\begin{array}{l}\text { Continuing } \\
\text { relationships } \\
\text { with patients }\end{array}$ \\
\hline \multicolumn{2}{|c|}{ Working hours (n) } & -0.163 & -0.178 & 0.103 & -0.061 \\
\hline \multirow{6}{*}{ Role } & Physiotherapist $^{\mathrm{b}}$ & - & - & - & - \\
\hline & Nurse $^{b}$ & -0.062 & $-0.380 * * *$ & $-0.207 *$ & -0.080 \\
\hline & Healthcare assistant $\mathrm{t}^{\mathrm{b}}$ & -0.074 & $-0.185^{*}$ & 0.026 & -0.115 \\
\hline & Office worker $^{\mathrm{b}}$ & - & - & - & - \\
\hline & Physician $^{\mathrm{b}}$ & 0.015 & -0.167 & $0.303 * *$ & 0.015 \\
\hline & Other profession $^{\mathrm{b}}$ & 0.105 & -0.078 & 0.142 & -0.027 \\
\hline \multirow{4}{*}{$\begin{array}{l}\text { Working } \\
\text { relationship }\end{array}$} & Permanent contract $^{\mathrm{b}}$ & - & - & - & - \\
\hline & Fixed-term contract ${ }^{\mathrm{b}}$ & 0.122 & 0.041 & 0.006 & -0.003 \\
\hline & Free lance $^{\mathrm{b}}$ & -0.083 & 0.035 & -0.138 & -0.099 \\
\hline & Others $^{\mathrm{b}}$ & 0.007 & 0.016 & -0.007 & 0.077 \\
\hline \multicolumn{2}{|c|}{ Prioritization of quality care } & $0.424 * * *$ & $0.307 * *$ & $0.218 *$ & $0.229 *$ \\
\hline \multicolumn{2}{|c|}{ Social cooperation and exchange } & $0.291 * *$ & 0.149 & $0.287 * *$ & $0.296^{*}$ \\
\hline \multicolumn{2}{|l|}{ R2 adj } & 0.415 & 0.228 & 0.318 & 0.196 \\
\hline \multicolumn{2}{|l|}{$F$} & $7.349 * * *$ & $3.653 * * *$ & $5.193 * * *$ & $3.160 * * *$ \\
\hline
\end{tabular}

Notes. ${ }^{\mathrm{a}} 1=$ male, 2 = female; ${ }^{\mathrm{b}} 0=$ no, $1=$ yes; $* p<0.05 ; * * p<0.01 ; * * * p<0.001$.

In order to assess the potential threat of collinearity, it was computed a variance inflation factor (VIF). The highest value of the VIF was 2.530; thus, all values were well below the cut-off point of 10 (Hair, Black, Babin, Anderson, \& Tatham, 2006), mitigating concerns of multi-collinearity. In all the four regression analyses, control variables were entered in a first block entry in order to assess their effective contribution in explaining different aspects of quality. In the second step, the two factors measuring quality-oriented climate were added in the equation. According to results shown in Table 4, the likelihood of providing high quality care to all patients depends on both dimensions of quality climate (Prioritization of quality care, $\beta=0.424, p<0.001$ and Social cooperation and exchange, $\beta=0.291, p<0.01$ ). Thus, Hypothesis 1 was completely supported. The results of this first regression demonstrate that when quality of care is perceived by healthcare workers as a priority for the organization, the level of quality care provided to the patient is higher in the professionals' perceptions. The perceived adequacy of time spent with patients during office visits is significantly affected by one dimension of quality-oriented climate that is prioritization of quality care $(\beta=0.307, p<0.01)$ while the dimension of social cooperation and exchange wasn't supported as being a predictor of adequacy of time spent with patients. About the control variable, the adequacy of time is negatively influenced by the role of the nurse $(\beta=-0.380, p<0.001)$, and by the role of healthcare assistant $(\beta=-0.185, p<0.05)$. Thus, hypothesis 2 was partially supported. The results of this second regression showed that the perception of healthcare workers of an organization oriented towards service quality facilitate the adequacy of time spent with patients. At the same time, the role of nurses and healthcare assistant show a significant and negative effect on the possibility to spend adequate time with patients. The freedom of professionals to make clinical decisions that meet patients' needs is influenced in a positive and significant way by the two dimensions of quality-oriented climate (prioritization of quality care, $\beta=$ $0.218, p<0.05$, and social cooperation and exchange, $\beta=0.287, p<0.01$ ). Holding a specific job role influences this variable, in particular nurses $(\beta=-0.207, p<0.05)$ and physicians $(\beta=0.303, p<0.005)$. In this case, the role of physicians is positively related to the dependent variable while one of nurses is negatively related to the 
freedom of professional to make clinical decisions. Hypothesis 3 was supported. Indeed, the possibility to meet patients' needs, thanks to the possibility of the freedom to make clinical decisions, depends on both aspects of an organizational climate oriented toward quality. Finally, continuing relationships with patients over time are influenced by the two dimensions of quality-oriented climate (Prioritization of quality care $\beta=0.229, p<0.05$ and Social cooperation and exchange, $\beta=0.296, p<0.05$ ). Hypothesis 4 was supported. Organizations that promote a high level of cooperation among all members, as well as a climate of trust, facilitate the development of continuing relationships with patients, which facilitates the provision of high-quality care. In summary, in order to promote quality in care provision, all the two aspects of the quality-oriented climate play an important role, as suggested by the results of correlation analysis and regression. The only exception is when healthcare workers' perception of the adequacy of time spent is considered. Indeed, despite this variable is affected by both the aspects of quality climate orientation, as demonstrated through correlation analysis, when both work climate variables are considered together, social cooperation and exchange lose its explanatory power while the other dimension remains significant.

The results of this study showed that, when an organization has implemented a quality-oriented climate, the service care provided by healthcare workers can determine an increase for three of the four investigated aspects that represent the "core" dimensions of quality service provision (quality of care, freedom to make clinical decisions to meet patients' needs, and continuing relationships with patients).

\section{Conclusion}

The evidences emerged from this research confirm that the offer of quality services involves, in a different way and with a different degree of participation and responsibility, the various healthcare professionals and/or the management staff. Indeed quality oriented organization appears to be the result of a share process between management and healthcare workers. Quality can also be considered as a fundamental tool and a sort of shared language within the logic of inter/multi/trans-disciplinary healthcare actions and processes. It is nowadays common to see many professionals being involved and responsible for the patients' care at the same time, and all of them must assure the highest professional level to gain the best results in terms of prevention, diagnosis, therapy, and rehabilitation. As above mentioned, quality is not only represented by the "typical" aspects of healthcare processes (technical quality) nor by the technical resources spent in these processes: it is a larger concept which embraces the relational component of the care for example the relationship between professional/patients, and the workplace climate.

The attention to service quality can represent, in such a critical context due to the reflections of the economic crisis on welfare systems and to the subsequent rationing of services and provisions, a useful keystone for the professionals, for healthcare organizations and the community as a whole. For professionals, it can be a way to disseminate quality culture, favor their development, and offer them support in achieving quality standard; for the healthcare organizations, it can represent a way to give accountability to all stakeholders (in particular patients, institutions, and employees) about the policies adopted to solve the healthcare problems to achieve results. The development of a favorable quality climate can therefore represent the better choice to support professionals in adopting a management approach oriented to the quality. This study has tried to explore some of these dimensions to better understand if the promotion of an effective quality climate may represent a lever to re-orient healthcare organizations towards quality. Despite the limits imposed by the specific context in which this analysis has been realized and the single case study analyzed, this work gives indications, but not findings that could be 
significant and generalizable for the healthcare system as a whole. It would be desirable that, as in other countries, also in Italy, the issue of service quality and its determinants would become an important field of research and training challenge for all healthcare professionals.

\section{References}

Babakus, E., \& Mangold, W. G. (1992). Adapting the SERVQUAL scale to hospital services: An empirical investigation. Health Services Research, 26(6), 767-786.

Brueller, D., \& Carmeli, A. (2011). Linking capacities of high-quality relationships to team learning and performance in service organizations. Human Resource Management, 50(4), 455-477. doi: 10.1002/hrm.20435

Choi, K. S., Lee, H., Kim, C., \& Lee, S. (2005). The service quality dimensions and patient satisfaction relationships in South Korea: Comparisons across gender, age and types of service. Journal of Services Marketing, 19(3), 140-149. doi: http://dx.doi.org/10.1108/08876040510596812

Degeling, P., Kennedy, J., \& Hill, M. (2001). Mediating the cultural boundaries between medicine, nursing and management-the central challenge in hospital reform. Health Services Management Research, 14(1), 36-48. doi: 10.1258/0951484011912519

Denison, D. R. (1996). What is the difference between organizational culture and organizational climate? A native's point of view on a decade of paradigm wars. Academy of Management Review, 21(3), 619-654. doi: 10.5465/AMR.1996.9702100310

Donabedian, A. (1988). The quality of care: How can it be assessed? Jama, 260(12), 1743-1748. doi: 10.1001/jama.1988.03410120089033

Donabedian, A. (2005). Evaluating the quality of medical care. Milbank Quarterly, 83(4), 691-729. doi: $10.1111 / \mathrm{j} .1468-0009.2005 .00397$

Field, A. (2009). Discovering Statistics Using SPSS: Introducing Statistical Method (3rd ed.). Thousand Oaks, CA: Sage Publications.

Gershon, R. R., Stone, P. W., Bakken, S., \& Larson, E. (2004). Measurement of organizational culture and climate in healthcare. Journal of Nursing Administration, 34(1), 33-40. doi: 10.1097/00005110-200401000-00008

Gittell, J. H. (2002). Coordinating mechanisms in care provider groups: Relational coordination as a mediator and input uncertainty as a moderator of performance effects. Management Science, 48(11), 1408-1426. doi: http://dx.doi.org/10.1287/mnsc.48.11.1408.268

Glickman, S. W., Baggett, K. A., Krubert, C. G., Peterson, E. D., \& Schulman, K. A. (2007). Promoting quality: The health-care organization from a management perspective. International Journal for Quality in Healthcare, 19(6), 341-348. doi: 10.1093/intqhe/mzm047

Grönroos, C. (1984). A service quality model and its marketing implications. European Journal of Marketing, 8, 36-44. doi: http://dx.doi.org/10.1108/EUM0000000004784

Hair, J., Black, B., Babin, B., Anderson, R., \& Tatham, R. (2006). Multivariate data analysis (6th ed.). Upper Saddle River, NJ: Prentice-Hall.

Hallowell, R., Schlesinger, L. A., \& Zornitsky, J. (1996). Internal service quality, customer and job satisfaction: Linkages and implications for management. Human Resource Planning, 19, 20-31.

Hussein, A. H. M. (2014). Relationship between nurses' and physicians' perceptions of organizational health and quality of patient care. Eastern Mediterranean Health Journal, 20(10), 634-642.

Kaissi, A., Kralewski, J., Curoe, A., Dowd, B., \& Silversmith, J. (2004). How does the culture of medical group practices influence the types of programs used to assure quality of care? Healthcare Management Review, 29(2), 129-138. doi: 10.1097/00004010-200404000-00006

Karassavidou, E., Glaveli, N., \& Zafiropoulos, K. (2011). Assessing hospitals' readiness for clinical governance quality initiatives through organisational climate. Journal of Health Organization and Management, 25(2), 214-240. doi: http://dx.doi.org/10.1108/14777261111134437

Kelley, E., \& Hurst, J. (2006). Healthcare quality indicators project conceptual framework paper. Health Working Papers, 23. Paris: OECD.

Lewin, K., Lippit R., \& White, R. (1939). Patterns of aggressive behaviour in experimentally created social climates. Journal of Social Psychology, 10, 271-299. doi: http://dx.doi.org/10.1080/00224545.1939.9713366

Morgan, P. I., \& Ogbonna, E. (2008). Subcultural dynamics in transformation: A multi-perspective study of healthcare professionals. Human Relations, 61(1), 39-65. doi: 10.1177/0018726707085945 
Navarro-Espigares, J. L., \& Hernandez Torres, E. (2011). Efficiency and quality in health services: A crucial link. The Service Industries Journal, 31(3), 385-403. doi: http://dx.doi.org/10.1080/02642060802712798

Nembhard, I. M., Northrup, V., Shaller, D., \& Cleary, P. D. (2012). Improving organizational climate for quality and quality of care: Does membership in a collaborative help? Medical care, 50, 74-82. doi: 10.1097/MLR.0b013e31826b1087

Nunnally, J. C. (1978). Psychometric theory (2nd ed.). New York, NY: McGraw-Hill.

Perleth, M., Jakubowski, E., \& Busse, R. (2001). What is best practice in healthcare? State of the art perspectives in improving the effectiveness and efficiency of the European healthcare systems. Health Policy, 56(3), 235-250. doi: 10.1016/S0168-8510(00)00138-X

Piligrimienè, Ž., \& Bučiūnienè, I. (2008). Different perspectives on healthcare quality: Is the consensus possible? Engineering Economics, 1(56), 104-110.

Reschovsky, J., Reed, M., Blumenthal, D., \& Landon, B. (2001). Physicians' assessments of their ability to provide high-quality care in a changing healthcare system. Medical care, 39(3), 254-269. doi: 10.1097/00005650-200103000-00006

Restuccia, J. D., Cohen, A. B., Horwitt, J. N., \& Shwartz, M. (2012). Hospital implementation of health information technology and quality of care: Are they related? BMC Medical Informatics and Decision Making, 12(1), 109. doi: 10.1186/1472-6947-12-109

Schneider, B., Brief, A. P., \& Guzzo, R. A. (1996). Creating a climate and culture for sustainable organizational change. Organizational Dynamics, 24(4), 7-19. doi: http://dx.doi.org/10.1016/S0090-2616(96)90010-8

Scotti, D. J., \& Harmon, J. (2014). Linkages between organization climate and work outcomes: Perceptual differences among health service professionals as a function of customer contact intensity. Journal of Health and Human Services Administration, 36(4), 417-459.

Shortell, S. M., O’Brien, J. L., Carman, J. M., Foster, R. W., Hughes, E. F., Boerstler, H., \& O’Connor, E. J. (1995). Assessing the impact of continuous quality improvement/total quality management: Concept versus implementation. Health Services Research, 30(2), 377-401.

Shortell, S. M., Zazzali, J. L., Burns, L. R., Alexander, J. A., Gillies, R. R., Budetti, P. P., \& Zuckerman, H. S. (2001). Implementing evidence-based medicine: The role of market pressures, compensation incentives, and culture in physician organizations. Medical Care, 39(7), 62-78.

Stichler, J. F., \& Weiss, M. E. (2001). Through the eye of the beholder: Multiple perspectives on quality in women's healthcare. Journal of Nursing Care Quality, 15(3), 59-74. doi: 10.1097/00001786-200104000-00009

Wallace, J. E. (1995). Organizational and professional commitment in professional and nonprofessional organizations. Administrative Science Quarterly, 40(2), 228-255. doi: 10.2307/2393637

Williams, E. S., Manwell, L. B., Konrad, T. R., \& Linzer, M. (2007). The relationship of organizational culture, stress, satisfaction, and burnout with physician-reported error and suboptimal patient care: Results from the MEMO study. Healthcare Management Review, 32(3), 203-212. doi: 10.1097/01.HMR.0000281626.28363.59

Young, G. J., Meterko, M. M., Mohr, D., Shwartz, M., \& Lin, H. (2009). Congruence in the assessment of service quality between employees and customers: A study of a public healthcare delivery system. Journal of Business Research, 62(11), 1127-1135. doi: 10.1016/j.jbusres.2008.08.004 